\title{
ESTIMATIONS OF THE WORK OF THE HEART DURING AND BETWEEN ATTACKS OF ANGINA PECTORIS
}

\author{
By ISAAC STARR, C. J. GAMBLE, J. S. DONAL, AND L. H. COLLINS \\ (From the Departments of Research Therapeutics, and of Pharmacology, and the Medical \\ Division of the Hospital of the University of Pennsylvania, Philadelphia)
}

(Received for publication January 12, 1938)

Angina pectoris is commonly attributed to a disproportion between the work demanded of the heart and the blood or oxygen supply available to it $(1,2,3,4,5)$. That the heart's work increases during the attack of pain has been inferred from several well known facts. First, increased blood pressure is common during the period of pain, although there is no complete correlation between the degree and duration of pain and the change in blood pressure $(6,7)$. Second, situations which commonly induce anginal attacks, such as exercise, excitement, food, and cold, increase the cardiac output of normal subjects $(8,9)$.

The duration of most spontaneous attacks of angina following effort is too brief to permit satisfactory estimations of cardiac output during the pain. Physicians have hesitated to induce attacks of cardiac pain of a duration sufficient to permit such estimations. Probably these reasons account for the lack of estimations of cardiac output in the huge literature on angina pectoris. Therefore the widely accepted view that angina is associated with increased heart work has never been verified by measurement.

During a long series of estimations of cardiac output, carried out on patients during the last eight years, we had several unexpected opportunities to study angina pectoris. These opportunities were seized. Therefore we have secured satisfactory estimations of cardiac output, metabolic rate, blood pressure, pulse rate, and respiration, during cardiac pain in four patients. Comparable estimations, when the patients were free of pain, were secured also.

Three of our patients had typical angina pectoris. Two have since died of their disease and in one a necropsy was secured. The fourth individual suffered from atypical cardiac pain apparently induced by digitalis.

In two instances we secured data on the physiological changes which accompanied the relief of pain after the administration of nitroglycerine.
In all of these patients the estimated work of the left ventricle was much larger during the pain than in its absence. Our one necropsy proved the coronary circulation to have been impeded. Therefore, our results support the generally accepted view of the causation of angina pectoris.

\section{METHODS}

Estimations of cardiac output and metabolic rate were performed in the manner described $(10,11)$. Left ventricular work has been calculated by the formula:Work $=$ cardiac output $\times$ mean blood pressure $\times 13.6$ (12). Patient W. B. had slight aortic regurgitation and in this case the estimation of work is too small, as the amount of blood leaking through the aortic valve is not included in the estimation of cardiac output. The increased blood pressure during pain would tend to increase the error and, although this would be somewhat offset by the decreased duration of diastole with the faster pulse rate, we believe that the actual increase of heart work during the pain must have been larger than our estimate of it.

Criteria discussed before (13) have permitted us to evaluate the significance of differences in cardiac output estimations in statistical terms.

The subjects were lying at rest $\mathbf{1 5}$ or more hours after their last meal. Ward patients were brought to the laboratory in a wheel chair and lay on the bed over $1 / 2$ hour before the first estimation. The one outpatient (W. B.) lay down for 1 hour before the first estimation.

\section{RESULTS AND DISCUSSION}

The results in Case L. S., in which we have observations of blood pressure and pulse rate just before pain began, have been set forth in detail in Figure 1. This was our most intelligent subject, and he was able to give a clear account of the variations in intensity of his pain. A very nervous individual, the attack was probably induced by excitement.

Table I gives the results secured in the other three patients. The action of digitalis was perhaps a factor in the induction of attacks in Cases W. B. and A. K. Estimations of cardiac output had been made previously on both these patients 


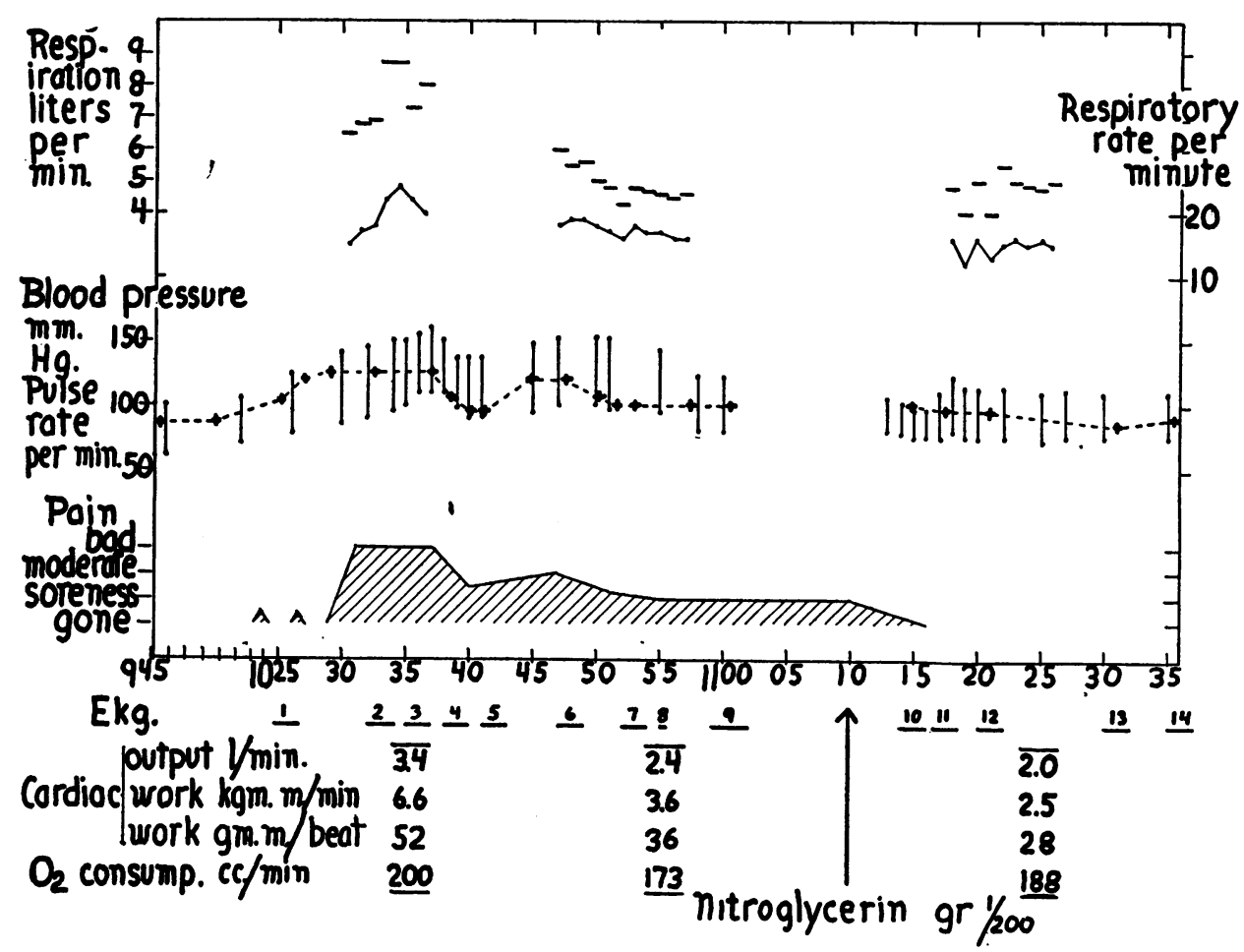

Fig. 1. Observations Made Before, During, and After an Attack of Angina Pectoris in Case L. S.

The figures given for cardiac work include only that part contributed by the left ventricle.

without causing them discomfort. In Case K. P. the attack was induced by adrenalin, given without knowledge that the patient had had angina previously.

In every case the work of the left ventricle was greater during the pain than when the patient was comfortable. When these results are averaged, the increase of work during the pain is statistically significant. Increased blood pressure was a factor in the elevation of the heart's work in every instance. Cardiac output increased in three of the four cases. This increase is significant in each of these cases, when the difference is judged by the standards which we have set for ourselves (13). In Case W. B. no change of cardiac output during pain was demonstrated, but the blood pressure rose to a level higher than that found in any other case.

In Patients L. S. and K. P. estimations were made during both mild and more severe pain. The results indicate that the greater the heart's work the more severe the attack, but we do not have sufficient data to make the differences significant.

Changes in oxygen consumption during the pain were usually small except after adrenalin, and when these results are omitted the average change is not significant.

Respiratory volume was usually larger during pain, Case W. B., after nitrites, being the only exception.

The pulse rate was faster during pain in three of the four cases, the slowing in the remaining case was due to digitalis.

After the pain had been relieved by nitroglycerine, the blood pressure and the heart's work were lower in both the patients to whom this drug was administered. After this drug the cardiac output was significantly lower in Case L. S. It was elevated, but not significantly, in Case W. B. The pulse rate fell markedly in both instances, a result the opposite of that which usually follows the administration of nitroglycerine to normal subjects. 
TABLE I

Data obtained during and between attacks of angina pectoris

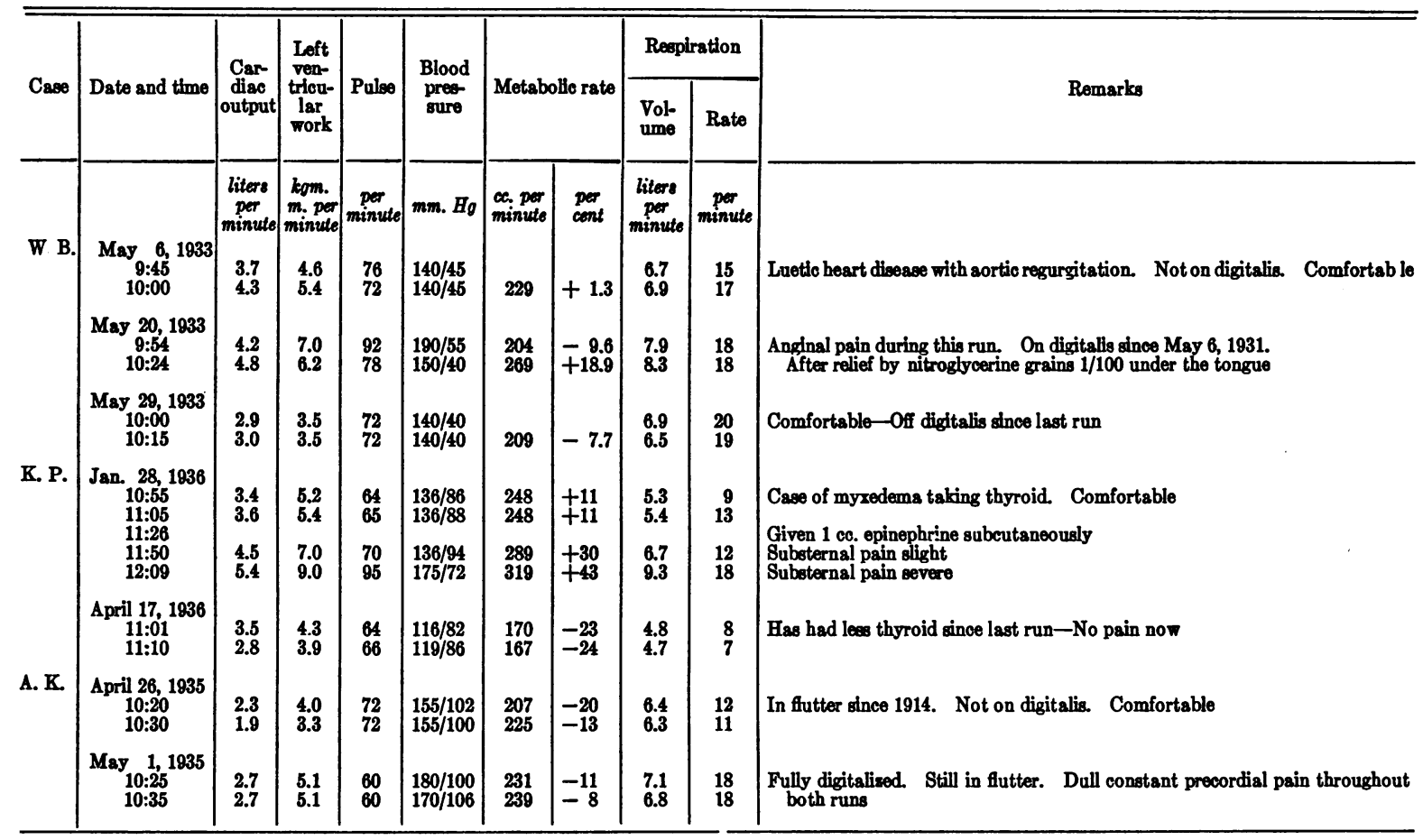

\section{SUMMARY AND CONCLUSIONS}

In four cases of cardiac pain, three of them suffering from typical angina pectoris, estimations of cardiac output, basal metabolic rate, blood pressure, pulse rate, and respiration were made during the pain and, under comparable conditions, when the patients were free from it. In one case a necropsy was secured. The changes following relief by nitroglycerine were studied in two cases.

The results indicate that the work of the heart was significantly greater during the pain than when the patients were free from it.

The results are consistent with the widely accepted view that cardiac pain is caused by situations demanding increased cardiac work when the heart's blood supply cannot be increased correspondingly.

\section{CASE REPORTS}

Case L. S. A white man, height $5 \mathrm{ft} .2$ in., weight 107 pounds, age 50 in 1931 . He had been well till 2 years before admission. Then, while doing hard physical work, he was seized by a severe attack of substernal pain lasting $1 / 2$ hour. Residual soreness for 3 days fol- lowed. After this attack he had frequent attacks of substernal "pain and pressure" on undue exertion, always less severe than the initial attack and lasting 5 to 10 minutes after cessation of activity. Nitrites afforded prompt relief, nitroglycerine was taken almost daily during the week prior to admission. Finally, on October 3, 1931, after a struggle with a refractory door in the outpatient department, he had such a severe pain that he was sent to the ward.

Physical examination revealed the following: A nervous individual, substernal pain passing off, hyperesthesia of upper portion of chest. Pulse 104, blood pressure $132 / 90$. Otherwise, examination was essentially negative. Orthodiagram-cardiac area $81 \mathrm{~cm}$. sq. (normal). Electrocardiogram-QRS split in Lead II, slurred in Lead III, deep $Q$ III, $T$ inverted in all leads.

On October 9, 1931, an estimation of cardiac output was planned. Shortly after beginning to breathe through the mouthpiece, he complained of substernal pain and coincidently blood pressure rose from $140 / 90$ to $170 / 110$. The estimation was abandoned and $0.3 \mathrm{mgm}$. nitroglycerine administered with prompt relief.

On October 12, 1931, a second attempt was made and Lead II of the electrocardiogram was connected also. He had no pain on arrival at the laboratory, but an attack developed during the inhalation of ethyl iodide, and the first estimation of cardiac output was made at its height. After this was over pain subsided but soreness persisted during the second estimation. A third estima- 
tion was made after nitroglycerine had completely relieved him. Figure 1 shows the results. The electrocardiogram showed nothing of interest.

He continued to have similar attacks in the Hospital. On October 31 he had a severe one during a gastro-intestinal $\mathbf{x}$-ray examination.

On November 6, 1931, he was seized with a severe pain about midnight, nitrites failed to relieve it and morphine was required. Electrocardiogram showed evidence of acute coronary thrombosis. He died 12 hours later. Necropsy was not permitted. Diagnosis: angina pectoris, coronary thrombosis.

Case W. B. A white man, 5 ft. 6 in. tall, weight 157 pounds, age 56 in 1933.

In 1931, the Wassermann was found to be strongly positive, the heart was enlarged (orthodiagram plus 27 per cent) with signs of aortic regurgitation of moderate degree. Blood pressure was 150/50. Antiluetic treatment was commenced and was continued, with intermissions, until his death.

In 1932, he began to have attacks of severe substernal pain, radiating down both arms, and induced by exertion. These attacks were relieved by nitroglycerine. He soon became unable to work, having anginal attacks on slight exertion several times a week.

On May 6, 1933, basal cardiac output was estimated uneventfully. After this, he was put on 0.15 gram of digitalis daily.

On May 20, 1933, a second estimation of basal cardiac output was performed after an hour's rest on the bed. He complained of substernal pain soon after inhalation had begun, and it persisted without great severity till the first estimation was completed. $\mathrm{He}$ was then given 0.6 mgm. nitroglycerine under his tongue which relieved the pain and restored the blood pressure to its previous level in 5 minutes. A second group of estimations was then performed. Table I gives the results. On conclusion he was told to discontinue digitalis.

A month later another duplicate estimation of basal cardiac output was made without discomfort.

During 1934, the anginal attacks grew steadily more frequent and severe. One day he needed 27 tablets of nitroglycerine.

In January 1935 , he was admitted to the ward in congestive failure. He died a week later.

Necropsy disclosed syphilitic aortitis and aortic valvulitis, hypertrophy and dilatation of the heart, an infarct of the lung, bilateral pleural effusions, and passive congestion of the abdominal viscera. The aperture of the left coronary artery was narrowed so that a small probe was admitted with difficulty, the right aperture was normal. The coronary vessels showed moderate yellow intimal thickening and were unobstructed.

Clinical diagnosis: Syphilitic heart disease with aortic valvulitis and regurgitation, angina pectoris, left coronary obstruction.

Case K. P. A white man, born in Poland, was $5 \mathrm{ft}$. 2 in. tall, 156 pounds in weight and 50 years old in 1936. He was well till 1928 when he developed vague pains in his limbs diagnosed as arthritis, which persisted, with numerous remissions, until admission in 1933. Deafness and failing vision were additional complaints. Physical examination revealed a man of very low intelligence, an appearance suggestive of myxedema, infected tonsils, a boggy prostate, and signs of mild arthritis of right knee and of interphalangeal joint of right thumb. The routine laboratory tests were negative. Basal metabolic rate was $\mathbf{-} \mathbf{5}$ per cent. Thyroid was not given. Tonsillectomy was performed, and the prostate massaged twice weekly. He was discharged improved.

In the summer of 1935 he began to complain of dyspnea on exertion, also of substernal pain on climbing stairs. He returned to the Outpatient Department in December where he was found to be much confused mentally with a basal metabolic rate of -33 per cent. He was given thyroid and, not doing well, was sent to the ward.

The patient was so dull that no history of angina was obtained on admission. Physical examination was essentially as before. Orthodiagram showed the heart to be 30 per cent larger than predicted. Electrocardiogram showed a PR interval of 0.16 second and small $T$ waves in all limb leads.

In ignorance of the presence of angina pectoris, the patient's cardiac output was estimated on January 28, 1936. After control estimations he was given $1 \mathrm{cc}$. of epinephrine subcutaneously and a second set of observations begun. Substernal pain began before any samples had been taken, and the first estimation was made while it was mild but increasing. The second estimation was made while pain was severe, and the blood pressure at its height. The blood pressure and pain diminished after the estimation had been completed, but slight distress and some elevation of blood pressure were still present 45 minutes later. $\mathrm{He}$ had no other attacks while in the Hospital.

He was discharged on a larger dose of thyroid and soon felt much better, but late in March 1936, having a number of indefinite complaints, he was readmitted. Basal metabolic rate was now -27 per cent. On April 17th basal cardiac output was estimated again, uneventfully. The results are given in Table $I$.

Since discharge, he has continued under supervision of the Outpatient Department. Therapy has been aimed both to keep him comfortable and to keep his metabolic rate low enough to prevent undue angina. This has been successfully accomplished.

At date of writing (1938), he is doing light work and reports that he has only infrequent attacks of substernal pain, never severe enough to require nitrites. Clinical diagnosis: Myxedema, angina pectoris.

Case $A . K$. A white man, 5 ft. 11 in. tall, 190 pounds in weight, age 59 in 1935.

Hyperthyroidism and subtotal thyroidectomy in 1912. Auricular flutter was diagnosed by electrocardiogram in 1914 and has persisted to date. During this period he was admitted to the ward repeatedly for headache, nervousness, palpitation, belching, constipation, and atypical precordial pain. This pain was often present for several days at a time. A dull ache, it was never 
severe, and did not radiate. No sense of constriction accompanied it. When present during rest, it was made much worse by exertion.

In 1935, increased shortness of breath led to his admission. Physical examination showed slight peripheral arteriosclerosis, râles at lung bases, enlarged heart (orthodiagram plus 42 per cent); electrocardiogram showed flutter with block varying from 2 to 1 , to 4 to 1 . Blood pressure averaged 190/115. The ventricular rate varied from 130 to 60 . X-ray suggested luetic osteoperiostitis of skull, left tibia, right fibula. The râles disappeared after a few days. The Wassermann was negative.

On April 26, 1935, the patient had received no digitalis for over a month. Duplicate estimations of basal cardiac output were performed uneventfully. After this he was placed on digitalis.

By May 1, 1935, he was fully digitalized but was suffering from precordial pain as described above. This persisted throughout both duplicate estimations of cardiac output. Table I gives the results.

After this date digitalis was discontinued. The pain soon disappeared, but the pulse became more rapid and irregular. Digitalis was begun again but precordial pain returned almost immediately. It was discontinued and relief followed again.

He left the hospital soon after and has not been seen since. Clinical diagnosis: Hypertensive cardiovascular disease, auricular flutter, atypical precordial pain.

\section{BIBLTOGRAPHY}

1. Keefer, C. S., and Resnik, W. H., Angina pectoris, a syndrome caused by anoxemia of the myocardium. Arch. Int. Med., 1928, 41, 769.

2. Sutton, D. C., and Lueth, H. C., Pain. Arch. Int. Med., 1930, 45, 827.

3. Lewis, T., Pain in muscular ischemia, its relation to anginal pain. Arch. Int. Med., 1932, 49, 713.
4. Fishberg, A. M., Heart Failure. Lea and Febiger, Philadelphia, 1937.

5. Rothschild, M. A., and Kissin, M., Production of the anginal syndrome by induced general anoxemia. Am. Heart J., 1932-33, 8, 729.

6. Lewis, T., Angina pectoris associated with high blood pressure and its relief by amyl nitrite with a note on Nothnagel's syndrome. Heart, 1931, 15, 305.

7. Wayne, E. J., and Laplace, L. B., Observations on angina of effort. Clin. Sc., 1933, 1, 103.

8. Starr, I., Jr., and Collins, L. H., Jr., Studies of cardiac output in normal men. Am. J. Physiol., 1931, 96, 228.

9. Grollman, A., The Cardiac Output of Man in Health and Disease. C. C. Thomas, Springfield, Ill., 1932.

10. Starr, I., Jr., and Gamble, C. J., An improved method for the determination of cardiac output in man by means of ethyl iodide. Am. J. Physiol., 1928, 87, 450.

11. Donal, J. S., Jr., Gamble, C. J., and Shaw, R., The cardiac output in man. An adaptation of the katharometer for the rapid determination of ethyl iodide in estimations of cardiac output by the ethyl iodide method. A study of the effect of posture upon cardiac output and other circulatory and respiratory measurements. Am. J. Physiol., 1934, $109,666$.

12. Starr, I., Jr., Collins, L. H., Jr., and Wood, F. C., Studies of the basal work and output of the heart in clinical conditions. J. Clin. Invest., 1933, 12, 13.

13. Starr, I., Gamble, C. J., Margolies, A., Donal, J. S., Jr., Joseph, N., and Eagle, E., A clinical study of the action of 10 commonly used drugs on cardiac output, work and size; on respiration, on metabolic rate and on the electrocardiogram. J. Clin. Invest., 1937, 16, 799. 